\title{
Distinct SOX9 Levels Differentially Mark Stem/Progenitor Populations and Enteroendocrine Cells of the Small Intestine Epithelium
}

\author{
Formeister, E.J., Sionas, A.L., Lorance, D.K., Barkley, C.L., Lee, G.H., Magness, S.T. ${ }^{\dagger}$ \\ *Department of Medicine, Division of Gastroenterology and Hepatology, University of North \\ Carolina at Chapel Hill
}

Running Head: Sox9 levels mark stem/progenitor and enteroendocrine cells

$\dagger$ - Corresponding Author: Scott T. Magness

University of North Carolina at Chapel Hill

101A Mason Farm Rd. CB\# 7032

MBRB Rm. 7332

Chapel Hill, NC 27599

Tel: 919-966-6816

Fax: 919-843-6899

e-mail: magness@med.unc.edu 


\section{ABSTRACT:}

SOX transcription factors have the capacity to modulate stem/progenitor cell proliferation and differentiation in a dose-dependent manner. SOX9 is expressed in the small intestine epithelial stem cell zone. Therefore, we hypothesized that differential levels of SOX9 may exist, influencing proliferation and/or differentiation of the small intestine epithelium. Sox9 expression levels in the small intestine were investigated using a Sox $9^{E G F P}$ transgenic mouse. Sox $9^{E G F P}$ levels correlate with endogenous SOX9 levels, which are expressed at two steady-state levels, termed Sox $9^{E G F P L O}$ and Sox $9^{E G F P H I}$. Crypt-based columnar cells are Sox $9^{E G F P L O}$ and demonstrate enriched expression of the stem cell marker, Lgr5. Sox $9^{E G F P H I}$-cells express Chromogranin-A and Substance-P but do not express Ki67 and Neurogenin3, indicating Sox $9^{E G F P H I}$-cells are post-mitotic enteroendocrine cells. Over-expression of SOX9 in a crypt cell line stopped proliferation and induced morphologic changes. These data support a bimodal role for SOX9 in the intestinal epithelium where low SOX9-expression supports proliferative capacity, while high SOX9-expression suppresses proliferation.

Key Words: SOX, intestinal epithelial development, stem cell, progenitor cell, enteroendocrine cell 


\section{INTRODUCTION:}

Complete renewal of the adult mammalian small intestinal epithelium occurs every 3 to 14 days and is driven by multi-potential stem cells located in the base of the crypts $(4,11)$. The impressive rate of tissue turnover requires well-coordinated maintenance of the stem cell pool and also the appropriate differentiation of the transit amplifying progenitors into the four mature post-mitotic lineages of the small intestine (7-11). While most progenitors differentiate into absorptive cells, a small minority of progenitors differentiates into the remaining three secretory cell types: goblet cells, enteroendocrine cells, and Paneth cells.

The multipotent stem cells and committed progenitor cells that give rise to the post-mitotic intestinal epithelium have been difficult to study due to the lack of specific biomarkers, animal models, and methods to isolate live stem/progenitor cell populations for gene expression analysis. The specific location of the small intestine epithelial stem cell has been thought for many years to be located at cell position +4 (as numbered from the bottom of the crypt up the crypt-villus axis) (4). This putative stem cell location was based on a slow cell division criterion of the cells at an average position of +4 using ${ }^{3} \mathrm{H}$-Thymidine and BrdU label retention assays, which do not assess the multipotency and self-renewal characteristics of a stem cell.

Recently, an elegant in vivo lineage tracing experiment, using Lgr5 as a biomarker, demonstrated that a population of multipotential intestinal epithelial stem cells localize to the very base of the crypt (cell positions 0, 1', 2', 4; as defined by (2) and have been previously characterized as crypt-based columnar cells (CBCs) $(4,9,11)$. More recently, lineage tracing has demonstrated that the polycomb group gene, Bmi1, which is expressed primarily in a pool of cells around the +4 region also has multipotent capacity but only in the proximal small intestine (36). Although it is not clear whether the 
$\mathrm{Lgr5}^{+}$and $\mathrm{Bmil}^{+}$cells are functionally equivalent, it has been hypothesized that one population may be a slower dividing 'quiescent' stem cell (cells at position +4) which gives rise to more rapidly dividing multipotent stem cells (the CBCs) $(24,34)$.

Nonetheless, both cell types are under the influence of intrinsic and extrinsic signals directing the decisions to self-renew and differentiate into all post-mitotic cell types of the small intestine epithelium. The intrinsic and extrinsic genetic pathways controlling the defining properties of stem cells, selfrenewal capacity and multipotency, are not fully understood in the intestine. Perhaps the most well studied pathways critical to the development and maintenance of the intestinal epithelium include the Wnt/ß-catenin and Notch pathways. When Wnt-signaling is engaged, a cascade of events leads to nuclear localization of $\beta$-catenin and transcriptional enhancement of target genes involved in supporting proliferation (i.e., c-myc, cyclin-D1). Genetic ablation of Wnt-signaling components results in crypt loss and the eventual disruption of intestinal epithelium homeostasis $(23,31)$.

Studies describing perturbations in normal Notch1-receptor signaling (by gain or loss of function) have likewise demonstrated the critical role of the Notch pathway in intestinal epithelial development, specifically in controlling the cell fate decisions of intestinal stem/progenitor cells (39, 46). When the Notch1-pathway is activated, its downstream target gene, Hes1, represses Math1 expression and promotes an absorptive cell fate over a secretory lineage fate. Negative disruption of the Notch1-pathway, either pharmacologically (41) or genetically, results in an aberrant increase in the numbers of secretory-cell lineages. Collectively, these studies indicate that precise control of the Wntand Notch1- pathways by modulating factors is critical for normal proliferation and differentiation of intestinal stem/progenitor cells.

A common feature of both the Wnt and Notch pathways is that they appear to be modulated by Sox $(\underline{\operatorname{Sr} y-B \underline{\text { ox}})}$ genes $(1,3,40)$, indicating a critical role for Sox-transcription factors in normal intestinal 
epithelium homeostasis. Sox genes are a family of at least 20 closely related transcription factors, which are defined by the presence of a HMG (High Mobility Group) domain (28). All Sox-factors bind a relatively loose consensus sequence, $(\mathrm{A} / \mathrm{T})(\mathrm{A} / \mathrm{T}) \mathrm{CAA}(\mathrm{A} / \mathrm{T}) \mathrm{G}(28)$, resulting in dramatic DNA bending $(37,44)$ that has been hypothesized to be critical for bringing distal control elements to proximal transcriptional start sites (44). SOX-factor competition for a single cis-control element combined with the physical interaction of SOX-factors with other transcription factors (45) influences the specificity of target gene transcription (21). The ability of SOX factors to bind the same consensus sequence has been linked to highly redundant function in some cell types $(14,19,27)$ and has obscured understanding the specific role of some SOX genes using gene-targeting technologies. The notion that multiple SOXfactors with differential capacities to modulate transcription are able to compete for transcriptional control of the same target gene points to the concept of how differential levels of SOX-factors in a single cell might influence proliferation or the outcome of lineage specification.

An interesting feature of SOX-factors is that they can function as dose-dependent regulators of stem/progenitor cell potency and competence $(33,40)$. Disruption in the proper balance of SOX-factor levels can result in severe congenital defects. Several conditions in humans and mice are caused by subtle changes in regulation or haplo-insufficiency of some Sox genes. For example, distinct hypomorphic levels of Sox2 result in esophageal atresia and tracheoesophageal fistula (33), and a range of eye phenotypes from anophthalmia to microphthalmia $(15,40)$. Likewise, the loss of a single Sox9 allele presents clinically as sex-reversal with Campomelic Dysplasia (22, 42). In both cases of SOXfactor deficiency, aberrant maintenance and differentiation of the stem/progenitor cell pool is causative to the clinical sequelae. Taken together, these reports indicate that discrete levels of SOX-factors play a critical role in normal differentiation of stem/progenitor cell populations. 
RT-PCR analysis demonstrates that Sox3, 4, 5, 7, 9, 10, 17 and 18 mRNAs are expressed in whole intestine preparations (5). Of these Sox-factors, Sox9 has been the most widely studied in the intestine. Expression of SOX9 protein has been localized to the stem cell and transit amplifying zones of the crypt (5). Interestingly, sporadic SOX9-expressing cells have also been reported to be located throughout the non-proliferating villus epithelium $(3,5,26)$.

Because distinct levels of SOX-factors appear to be critical for proper proliferation and differentiation in stem cell biology, we hypothesized that differential SOX9 expression may be playing a similar role in stem/progenitor cell populations in the intestine. To explore this possibility we utilized a BAC transgenic SOX9 ${ }^{\mathrm{EGFP}}$ animal model where EGFP is expressed by the regulatory regions of Sox9. In this study we examine both the Sox9 transcriptional activity (via EGFP expression) and endogenous levels of SOX9 protein throughout the crypt/villus axis of the small intestine. Additionally, we investigate the molecular characteristics and cellular identities of Sox9-expressing stem/progenitor cells and post-mitotic populations, and test whether increasing the levels of SOX9 is able to confer phenotypic changes in a non-transformed intestinal epithelial crypt cell line. The results of this study provide further insight into a function for Sox 9 in both the stem/progenitor cell populations, and in a subset of post-mitotic cells in the crypts and villi. 


\section{MATERIALS AND METHODS:}

\section{Mice/Genotyping}

The Sox $9^{E G F P}$ mouse line was originally generated as part of the GENSAT Brain Atlas Project (17) and contains genomic integration of a modified BAC (RP32-140D18) with 75.5 kb upstream and $\sim 151 \mathrm{~kb}$ downstream sequence to Sox9. Frozen Sox $9^{E G F P}$ mouse embryos were obtained from the Mutant Mouse Regional Resource Center (University of California-Davis) and reconstituted by transfer into foster mice. All mice are on the outbred CD-1 strain and were maintained as heterozygotes on the CD-1 genetic background. Mice breed normally and live to adulthood with no overt phenotypes due to the transgene. At 12 days post-natal, tail snips were viewed under an epi-fluorescent microscope fitted with filters for EGFP visualization. A high level of EGFP fluorescence compared to transgene negative control mice was scored as a positive for the Sox $9^{E G F P}$ transgene.

\section{Immunostaining/Microscopy:}

For tissue preparation, small intestines were dissected from adult Sox $9^{E G F P}$ mice ( $>8$ weeks of age) and luminal contents were flushed-out with PBS followed immediately by a single flush with freshly made $4 \%$ paraformaldehyde (PFA). The intestine was opened along the duodenal-ileal axis, placed on filter paper, and fixed for an additional $14-18$ hours at $4^{\circ} \mathrm{C}$. The tissues were then prepared for cryosectioning by immersion in $30 \%$ sucrose solution for at least 24 hours at $4^{\circ} \mathrm{C}$. Tissues were then embedded in Optimal Cutting Temperature (OCT) medium and frozen on dry ice. The OCT blocks were stored at $-80^{\circ} \mathrm{C}$ until cryosectioning. Thin sections $(8-10 \mu \mathrm{m})$ were cut on a cryostat and placed on positively charged microscope slides for staining and microscopy. This tissue preparation technique is critical for preserving the EGFP fluorescence. 
For immunostaining, the sections were washed twice in PBS to remove OCT, followed by incubation in blocking medium (5\% normal goat serum (NGS), in PBS-0.3\% Triton-X100) for at least 30 minutes at room temperature $\left(21-25^{\circ} \mathrm{C}\right)$. Primary antibodies were applied to the tissue sections in antibody staining solution (1\% NGS, in PBS-0.3\% Triton-X100). Dilutions were as follows: $\alpha$ EGFP (chicken, 1:500, Aves Labs, Inc. GFP-1020), aSOX9 (rabbit, 1:1000, Chemicon, Temecula, CA, AB5535), $\alpha$ NGN3 (rabbit, 1:250, Chemicon, AB5684), $\alpha$ Substance-P (rat; 1:500, Chemicon, MAB356), $\alpha$ Chromogranin-A (rabbit, 1:500, Immunostar, 20086), $\alpha$ Ki67 (mouse, 1:100, Dako, Carpinteria, CA M7249), $\alpha$ Lysozyme (rabbit, 1:1000, Diagnostics Biosystems, Pleasanton, CA, RP 028). All secondary antibodies ( $\alpha$ Rabbit-Cy3, Sigma, Saint Louis, MO, C2306; $\alpha$ Rabbit-Alexafluor 488, Molecular Probes, Eugene, OR, Z-25302; $\alpha$ Rat-Alexafluor 555, Molecular Probes, Z-25305) were used at a 1:500 dilution in staining buffer. For Ki67 it was necessary to amplify the signal using $\alpha$ Mouse IgG-Biotinylated (1:200, Jackson Immunoresearch Labs, West Grove, PA) followed by AlexFluor-555 labeled streptavidin (1:250, Molecular Probes, S32355). Antigen retrieval using Reveal Buffer (Biocare Medical, Concord, CA, RV1000L2J) was required for NGN3, Ki67, and Chromogranin A. Nuclei were stained with Draq5 (1:10,000, Biostatus, Ltd, San Diego, CA, BOS-889-001). Background staining was negligible as determined by non-specific IgG staining. Unless otherwise noted, co-staining/positive staining statistics were generated from cells from at least 50 crypts/villi.

For whole mount staining of crypts, whole crypts were isolated as described in the 'Epithelium Dissociation' section of the methods without the Dispase treatment. Approximately, 500 crypts were fixed in $4 \%$ PFA at $4^{\circ} \mathrm{C}$ for $\sim 18$ hours, then washed 5 times with PBS. For all wash procedures, crypts were gently mixed and allowed to settle to the bottom of tube (and not centrifuged). Washes and staining buffers were removed from crypts by gentle suction. Crypts were blocked in $500 \mu$ l of 5\% NGS/PBS-T for 1 hour at room temperature. Primary antibodies were added to $500 \mu \mathrm{l}$ of staining buffer and allowed 
to incubate for $\sim 18$ hours at $4^{\circ} \mathrm{C}$. The crypts were then washed 5 times with $1.5 \mathrm{mls} \mathrm{PBS}-\mathrm{T} / \mathrm{wash}$. Secondary antibodies (already described) were added 1:500 in 1\% NGS/PBS-T and incubated at room temperature for at least 2 hours. The secondary antibodies were removed and the crypts were washed 5 times with PBS-T for 30 minutes each. For co-staining with $\alpha$ Lysozyme and $\alpha$ SOX9 it was necessary to label the Lysozyme antibody with Alexafluor 488 using the Zenon primary antibody labeling kit (Invitrogen). Staining for SOX9 was conducted first followed by staining for Lysozyme. Nuclei were stained with Draq5.

Epifluorescent images were captured on an Olympus IX70 fitted with an Olympus digital camera. Objective lenses used were 20X and 40x with numerical apertures of 0.55 and 1.40 respectively. All confocal images represent $1.5 \mu \mathrm{m}$ optical sections unless otherwise noted and crypts were captured using confocal optical Z-sectioning (1.0 $\mu \mathrm{m}$ optical sections) and compiled using Zeiss LSM Image Software (Zeiss, Thornwood, NY). Objective lenses for the confocal images were 40X with a numerical aperture $=0.1$

\section{Immunoblotting}

Whole cell lysates were made from virus infected IEC-18 cells by adding RIPA buffer (0.15 M $\mathrm{NaCl}, 50$ mM Tris-Cl, pH-7.2, 1\% deoxycholic acid, 1\% Triton-X 100, 0.1\% SDS) and 1X protease inhibitors (Sigma, P8340) to two $15 \mathrm{~cm}$ plates. Prior to cell lysis, virus infected cells had been selected for stable transgene integration using puromycin selection for 10-days. Whole cell lysates were separated on a 10\% SDS-PAGE gel and proteins were transferred to PVDF membrane (Hybond LFP; GE Healthcare, Piscataway, NJ). The membranes were probed with anti-c-MYC (SC-40; Santa Cruz Biotech), anti-PCNA (MAB424R; Chemicon), and anti-ß-actin (A5316; Sigma), blocking in BLOTTO (5\% dried milk in Tris-buffered Saline-Tween, 0.75\%; TBS-T) for 30 minutes followed by incubation 
with primary antibodies diluted in BLOTTO. Primary antibodies were detected with anti-IgGHorseradish peroxidase conjugated secondary antibodies diluted in BLOTTO. The membranes were then incubated in the HRP detection agent (ECL, GE Healthcare) for five minutes and then exposed to film. Films were scanned on a flatbed film scanner to generate digital images.

\section{Epithelium Dissociation/FACS:}

To isolate intestinal crypt cells for Fluorescence Activated Cell Sorting (FACS), small intestine epithelium was dissociated into single cells essentially as previously described (13) with slight modifications. For FACS experiments mouse intestine were flushed with cold phosphate-buffered saline (PBS), cut open lengthwise in approximately $10 \mathrm{~cm}$ long pieces, and immersed in $\mathrm{PBS} / 30 \mathrm{mM}$ ethylenediaminetetraacetic acid (EDTA)/1.5 mM dithiothreitol (DTT) over ice for 20 minutes. The solution was disposed of and the tissue was shaken vigorously in fresh PBS/30 mM EDTA for approximately 30 seconds before being incubated at $37^{\circ} \mathrm{C}$ for 10 minutes. Intact tissue was discarded and dissociated crypts and villi were pelleted at $2500 \mathrm{rpm}$ for 5 minutes. The cells were washed twice with cold PBS, resuspended in Hank's buffered saline solution (HBSS) $/ 0.3 \mathrm{U} / \mathrm{mL}$ dispase at $37^{\circ} \mathrm{C}$ and shaken approximately every 2 minutes for 10 minutes. Then, fetal bovine serum (FBS, 5\%) and $100 \mu \mathrm{g}$ DNaseI was added before the cells were passed through a $70 \mu \mathrm{m}$ filter. Cells were pelleted at $2500 \mathrm{rpm}$ for 5 minutes and resuspended in $4 \mathrm{~mL}$ HBSS with 5\% FBS, then passed through a $100 \mu \mathrm{m}$ filter and combined with an additional $100 \mu$ g DNaseI. Equivalent numbers of cells from three animals were combined prior to FACSorting. Sox $9^{\text {EGFPNEGATIVE }}$, Sox $9^{\text {EGFPHI }}$, and Sox $9^{\text {EGFPLO }}$ cells were isolated using a MoFlo FACS machine (Dako/Cytomation). Cells were collected in ice cold HBSS and kept on ice throughout the sort. Time between death of the mouse to RNA extraction was kept to 3.5 to 4 hours to ensure the highest quality of RNA. 


\section{cDNA Preparation/Real-time PCR Analysis:}

cDNA from approximately $5 \times 10^{4}$ cells from each FACSorted population (Sox $9^{\text {EGFPNEGATIVE }}$,

Sox $9^{E G F P H I}$, and Sox $9^{E G F P L O}$ ) was made using RNAqueous Micro Kit (Ambion, Austin, TX) according to the manufacturer's protocols. Real-time PCR was conducted for each sample in triplicate on approximately $1 / 20,000$ of the total amount of cDNA generated. Taqman probes (Hes1, Mm00468601_m1; Notch1, Mm00435245_m1; Lgr5, Mm00438890_m1; Msi1, Mm00485224_m1; Sox9, Mm00448840_m1; 18S, HS99999901) for each gene were obtained from Applied Biosystems (Pleasanton, CA) and used in reactions according to the manufacture's protocol. 18S ribosomal RNA was amplified and used as the internal control gene for sample comparison. Delta CT values were calculated to obtain fold-changes for sample comparison (30).

\section{Lentivirus Production/Cell Culture:}

The lentiviral vectors were constructed using the plasmid backbone, pLVX-Puro, from Clontech (Madison, WI). To generate the pLVX-SOX9-EGFP vector, the coding sequence for murine SOX9 was cloned into the polylinker of a shuttle vector just 5' of an internal ribosomal entry site (IRES) linked to EGFP coding sequence. The SOX9-IRES-EGFP DNA fragment was then cloned into the pLVX-Puro vector. The control viral vector, pLVX-EGFP, contains all the elements of pLVX-SOX9-EGFP minus the SOX9 coding sequence. High titer lentivirus was generated according the Lenti-X system specifications (ClonTech).

The IEC-18 cell line was cultured in medium according to previously established optimal conditions (18): high-glucose Dulbecco’s Modified Eagle Medium (DMEM-H), 10\% Fetal Bovine Serum, 0.1\% Zinc/Insulin (Gibco, Grand Island, NY), $10 \mathrm{U} / \mathrm{ml}$ penicillin/streptomycin and $2 \mathrm{mM}$ L-glutamine. At 
$\sim 80 \%$ cell confluence, the medium was replaced with the normal medium containing the lentivirus and polybrene at $4.0 \mu \mathrm{g} / \mathrm{mL}$ for overnight transduction. At $48 \mathrm{hr}$., approximately $75 \%-80 \%$ of the cells were infected as assessed by EGFP fluorescence. The transduction medium was replaced after 24 hours with the standard IEC-18 medium. After 48 hours the cells were puromycin-selected (at $2.0 \mu \mathrm{g} / \mathrm{mL}$ ) in the standard IEC-18 culture medium. Selection continued for 10 days with cells analyzed daily for EGFP levels and morphology by microscopy. 


\section{RESULTS:}

\section{Sox $9^{E G F P}$ is expressed primarily in the base of the crypt in non-Paneth cell populations}

The Sox $9^{E G F P}$ mouse was originally generated as part of the GENSAT brain-mapping project and constructed by insertion of a bacterial artificial chromosome (BAC) into the mouse genome (17). The BAC containing the Sox9 locus was genetically modified to introduce the EGFP coding sequence just 5' of the Sox9 transcriptional start site, thus destroying any transgenic expression of Sox9 from the BAC. The Sox $9^{E G F P}$ mice breed normally and do not have any deleterious phenotype resulting from EGFP transgene expression.

Upon initial examination of the small intestine, we observed a restricted expression pattern of EGFP that localized exclusively to epithelial cells primarily at the base of the crypt in the Paneth cell zone (Figure 1A). As has been previously reported (5), we also observed sporadic Sox $9^{E G F P}$ positive cells in the villus (Figure 1B). This expression pattern of the Sox $9^{E G F P}$ transgene was observed throughout the duodenal-ileal axis. No Sox $9^{E G F P}$ expression was observed in the lamina propria, muscularis, bone marrow or circulating lymphocytes (as assessed by flow cytometry).

Upon further examination of the crypts using brightfield microscopy, Sox $9^{E G F P}$ appeared to be mostly expressed in a cell population that was intercalated between the granulated Paneth cells and supra-Paneth cell location but not in Paneth cells themselves (Figure 1C). To rule out the possibility that a small sub-set of Sox $9^{E G F P}$-expressing Paneth cells might have been overlooked in a thin cryostat section using Paneth cell morphology as an identifying criterion, we co-stained whole crypts for the Paneth cell marker, Lysozyme (6), and conducted three-dimensional (3-D) confocal microscopy. Threedimensional reconstruction of the entire crypt demonstrates that $\operatorname{Sox} 9^{E G F P}$ is expressed in all cells at the 
base of the crypt except Paneth cells. (Figure 1D, Supplemental Figure S1). Thus, a population of Sox $9^{E G F P}$ positive cells in the crypt base appears to be consistent with intercalating crypt-based columnar cells (CBCs).

\section{Sox $9^{\text {EGFP }}$ is expressed at two discrete levels}

Consistent with our hypothesis, there are two distinct levels of Sox $9^{E G F P}$ expression, termed $\operatorname{Sox} 9^{E G F P H I}$ and Sox $9^{E G F P L O}$, in the base of the crypt (Figure $2 \mathrm{~A}$ ). To establish whether endogenous SOX9 levels correlated with Sox $9^{E G F P}$ transgene levels, we stained Sox $9^{E G F P}$ small intestines for SOX9 protein. One-micron confocal microscopy slices demonstrate a direct correlation between the graded levels of Sox $9^{\text {EGFP }}$ and endogenous SOX9. Empirical evidence suggested that the Sox $9^{\text {EGFP }}$ high cells were concentrated in a supra-Paneth cell region, a region traditionally accepted as part of the stem cell niche. To quantify this observation we counted the position of Sox $9^{E G F P H I}$ cells using the standard cell numbering scheme where cell position 1 is at the base of the crypt (Figure 2B). Additionally, we assessed the total number of Sox $9^{E G F P H I}$ cells from the crypt base to the villus junction in intact crypt preparations. The results indicate there are between 1 and 6 Sox $9^{\text {EGFPHI }}$ cells per crypt (mean=3.1;S.E.M=1.4) and that most Sox $9^{\text {EGFPHI }}$ cells localize to position +4-6 (average +5) (Figure 2C). On the villus, all Sox $9^{E G F P}$ positive cells had a Sox $9^{E G F P H I}$ status and did not appear to be clustered in any particular region or pattern.

\section{Distinct SOX9 expression signatures define two populations of Paneth cells}

Several investigations have associated SOX9 immunostaining with granulated Paneth cells, however, Sox9 mRNA expression in Paneth cells has never been established $(3,5,26)$. Although it 
appears from these previous studies that SOX9 protein is expressed in some Paneth cells, it is unclear in the absence of a second genetic biomarker whether the nuclear staining is in the Paneth cells or the intercalating CBCs. In light of the absence of any Sox ${ }^{E G F P}$ expression in Lysozyme positive cells (Figure 1D), we indeed questioned whether there was SOX9 protein expression in the entire Lysozyme positive Paneth cell compartment. Using 3-D confocal imaging of intact crypts we demonstrate there are two populations of Paneth cells (defined as Lysozyme ${ }^{+} \mathrm{SOX9}^{+}$or Lysozyme ${ }^{+} \mathrm{SOX} 9^{-}$) existing in a 1:1 ratio per crypt (Figure 2D, Supplemental Figure S2). Neither of these two populations appears to localize to a particular region of the base of the crypt (i.e., at the very base of the crypt or higher up the crypt axis). One possible interpretation for the lack of Sox $9^{E G F P}$ expression in the SOX9 $9^{+}$Paneth cells is that the cis-regulatory elements controlling Sox9 expression in Paneth cells are not present in the Sox9 BAC clone used to generate the mice.

\section{Sox ${ }^{E G F P L O}$ cells demonstrate enhanced signaling for maintenance of 'stemness'}

To better characterize the 'stemness', genetic and cellular differences between Sox9 ${ }^{E G F P L}$ and Sox $9^{E G F P H I}$ cells, we investigated the expression of Notch1-pathway genes. Studies in stem/progenitor cells indicate that decreases in Notch1 receptor signaling lead to decreases in Hes1-repression of Math1, thus pushing stem/progenitor cell fate towards a secretory lineage $(16,38,39$, 46). To determine whether there was differential Notch1 expression and downstream signaling between Sox $9^{E G F P H I}$ and Sox $9^{E G F P L O}$ cells, we assessed the mRNA levels for Notch1 and its downstream target gene, Hes1, in these two cell populations. Small intestine epithelium was dissociated and the single cells were FACSorted based on either Sox $9^{E G F P L O}$ or Sox $9^{E G F P H I}$ expression status. Real-time semi-quantitative PCR was used to assess relative mRNA levels between the two samples (Figure 3A). The data show 
there is a 5-fold enrichment of Sox9 mRNA in Sox $9^{\text {EGFPHI }}$ cells compared to Sox $9^{\text {EGFPLO }}$ cells validating the EGFP intensity-based cell sorting. The data also demonstrate there is a 10-fold enrichment of Notch1 mRNA in Sox $9^{E G F P L O}$ cells with a concomitant 11-fold increase in Hes1, the downstream target of Notch-signaling (Figure 3B). These data indicate that the Notch1 pathway is activated to higher degree in Sox $9^{E G F P L O}$ cells suggesting secretory lineage fate is being suppressed and an uncommitted state and/or absorptive fate is being maintained in Sox $9^{E G F P L O}$ cells.

\section{Sox $9^{E G F P L O}$ cells demonstrate enriched levels of 'stemness' gene expression}

Two characteristics of Sox $9^{E G F P L O}$ cells suggest they in part comprise the multipotent stem cell population. These characteristics include: 1) the localization of Sox $9^{E G F P L O}$ to the intercalating crypt based columnar cell population, and 2) an active Notch1 pathway, which generally indicates suppression

of secretory lineage differentiation (16). To further characterize the genetic signatures of Sox $9^{E G F P L O}$ cells, we assessed gene expression patterns for other putative intestinal stem cell biomarkers in Sox $9^{E G F P L O}$ FACSorted cells (Figure 3C). The data show enriched expression of the multipotent stem cell marker, $\operatorname{Lrg} 5$ (2), in Sox $9^{E G F P L O}$ cells as compared to the Sox $9^{\text {EGFPNEGATIVE }}$ population. Additionally, the mRNA for another putative intestinal stem cell marker, Musashi1 (32), was enriched in Sox $9^{\text {EGFPLO }}$ cells (Figure 3C).

\section{Sox $9^{\text {EGFPHI }}$ cells are mature/post-mitotic enteroendocrine cells}

The decrease in Notch1-signaling in Sox $9^{E G F P H I}$ cells compared to Sox $9^{E G F P L O}$ cells (Figure 3B) led us to hypothesize that $\operatorname{Sox} 9^{E G F P H I}$ cells would be fate restricted to a secretory lineage. Because the 
Notch1 pathway activation appeared to be suppressed in the Sox $9^{E G F P H I}$ cells, we predicted the lineage identity of this population would be either goblet or enteroendocrine cells. Paneth cell-lineage was ruled out because of the location of Sox $9^{E G F P H I}$ cells along the crypt-villus axis, a non-Paneth cell morphology, and the lack of co-localization with the Paneth cell marker, Lysozyme (Figure 1D). To identify the lineage of Sox $9^{E G F P H I}$ cells we stained the small intestine of Sox $9^{E G F P}$ mice with goblet marker, MUC2, and enteroendocrine markers, Substance-P and Chromogranin-A. No co-localization was observed with MUC2, indicating that Sox $9^{\text {EGFPHI }}$ cells are not of the Goblet lineage (data not shown). However, the results clearly demonstrate co-localization of Sox $9^{E G F P H I}$ cells with the enteroendocrine cell markers, Substance-P (61\% colocalized) and Chromogranin-A (100\% colocalized) (Figure 4A and 4B).

To assess whether the Sox $9^{E G F P H I}$ cells in the crypts were immature cycling enteroendocrine precursors we stained small intestine from Sox $9^{E G F P}$ mice with Neurogenin3 (a biomarker of secretory/enteroendocrine progenitors) and the general proliferation marker, Ki67. We never detected colocalization of $N g n 3$ or Ki67 with Sox $9^{E G F P H I}$ in the adult small intestine (Figure 4C and 4D). These data, combined with the observation of Substance-P/Chromogranin-A expression in Sox $9^{\text {EGFPHI }}$ cells, indicate that Sox $9^{E G F P H I}$ cells are mature enteroendocrine cells.

\section{Increasing SOX9 levels in an intestinal progenitor cell line halts proliferation and elicits morphologic} changes

To define a functional role for increased levels of SOX9 enteroendocrine differentiation, we developed a gain-of-function assay in a non-transformed small intestine epithelial crypt cell line, IEC18. Spontaneous differentiation of the IEC-18 cells into enteroendocrine-like cells has been demonstrated indicating the multipotent capacity of these cells in culture (18). Based on the exclusive 
expression of high SOX9 levels in non-cycling enteroendocrine cells in vivo, we predicted that increasing the levels of SOX9 beyond a particular threshold might fate specify these cells to an enteroendocrine-like fate and/or halt proliferation. To test this hypothesis we generated a lentiviral vector in which the constitutive CMV promoter drives Sox9 cDNA expression (Figure 5A). The recombinant lentiviral transduction results in stable integration of the Sox9 cDNA transgene into the IEC-18 genome and high levels of SOX9 expression (Figure 5B). After positive selection with puromycin, equal numbers of control- or SOX9-virus infected IEC-18 cells were plated and allowed to grow over a 10-day period. Control-virus infected cells proliferated normally, growing to a confluent monolayer, whereas SOX9-virus infected cells remained viable as single cells with no clonal populations appearing on the plate (Figure 5C). Additionally, Western-blot analysis demonstrated a decrease in Proliferating Cell Nuclear Antigen (PCNA), and also a decrease in c-MYC, a downstream target of ß-catenin signaling that supports proliferation (Figure 5D).

A second striking observation was a distinct morphological change in SOX9-virus infected cells (Figure 5D \& 5E). Between 8-10 days post infection, IEC-18 cells expressing high levels of SOX9 transitioned from a typical IEC-18 epithelial cell morphology (small, uniform, flat cell body), to a morphology that resembled neuroendocrine morphology with a condensed cell body, dendritic/axonallike projections (Figure 5E), and/or possessing multiple vesicles (Figure 5F). These cells remained adherent and survived in culture until completion of the 10-day experiment. To determine if SOX9infected IEC-18 cells had differentiated into enteroendocrine cells, we immunostained these cells for mature enteroendocrine markers Chromogranin A and Substance P. Neither Chromogranin A nor Substance P antibodies demonstrated cross-reactivity with SOX9-virus infected cells (data not shown) indicating that SOX9-virus infected cells had not fully differentiated into mature enteroendocrine cells. 


\section{DISCUSSION:}

The phenotypic effects of differential transcription factor levels have recently been the focus of several studies, which illustrate the importance of this biological property during the development of several tissues $(15,22,33,40,42)$. In this study we utilized a transgenic reporter gene mouse to determine whether Sox9 was expressed at different levels in cells of the small intestinal epithelium. Our results indicate that there are two discrete steady-state levels of Sox9 mRNA and protein in the adult intestinal epithelium (now termed Sox $9^{L O W}$ and Sox $9^{\mathrm{HIGH}}$ ). Sox $9^{\mathrm{LOW}}$ expressing cells exist in the lower crypt, whereas $\operatorname{Sox} 9^{\mathrm{HIGH}}$ expressing cells are distributed primarily in the cell $+4-6$ position of the crypt and also sporadically throughout the villus epithelium. Our study shows that $\operatorname{Sox} 9^{L O W}$-expressing cells are in part intercalated between the Paneth cells in the CBC population. Three-dimensional confocal crypt reconstruction showing Sox $9^{L O W}$-expression in CBCs, combined with gene expression analysis showing enriched $\operatorname{Lgr5}$ expression in Sox $9^{L O W}$ cells, demonstrates that Sox $9^{L O W}$ cells include the $L g r 5^{+}$ multipotent stem cell population. Currently, an Lgr5 antibody that is able to detect mouse LGR5 does not exist thus precluding formal immunostaining analysis of the Sox ${ }^{L O W}$ population. Sox $9^{H I G H}$ cells in the crypt and villus are Chromogranin- $\mathrm{A}^{+}$Ki67', post-mitotic enteroendocrine cells. Gain-of-function studies in the IEC-18 intestinal crypt cell line indicate that high levels of SOX9 are involved in repressive modulation of proliferation in intestinal epithelial cells, and are perhaps influencing enteroendocrine cell fate specification.

Conditional deletion of Sox9 at E10.5 has been shown to ablate the Paneth cell population in the adult mouse $(3,26)$. An interesting observation from our study is that the Sox $9^{E G F P}$ transgene is never expressed in the Paneth cell population yet 50\% of Paneth cells express SOX9 protein. Due to the rapid generation of the intestinal epithelium, a reasonable interpretation is that transcription from the Sox9 
gene is terminated prior to Paneth cell differentiation and that SOX9 protein remains stabilized in 'younger’ Paneth cells. In 'older' Paneth cells SOX9 has degraded and results in a Lysozyme ${ }^{+} /$SOX9$^{-}$ population. The expression of SOX9 protein in only half of the Paneth cells may point to a unique role for the two populations in normal gut homeostasis, or implicate the requirement for SOX9 protein during the final stages of Paneth cell fate specification just prior to terminal differentiation and/or maturation at which time SOX9 is degraded.

Our results clearly indicate that high levels of SOX9 are expressed in the enteroendocrine compartment of the small intestine epithelium. However, unlike the Paneth cell lineage, SOX9 expression does not seem to be required for differentiation of enteroendocrine cells since there are no observable differences in the number of Chromogranin-A positive cells in an intestinal epitheliumspecific knockout for SOX9 (26). It might be predicted, because of the high levels of SOX9 specifically in enteroendocrine cells, that SOX9 normally influences the generation of the enteroendocrine cell lineage but its conditional loss at E10.5 is being compensated for by other SOX-factors. By contrast, no such compensation exists for Paneth cell differentiation as demonstrated by both Sox9-conditional knockout studies $(3,26)$.

The literature is replete with examples of Sox-factor redundancy. For example, Sox1, Sox2 and Sox3 appear to functionally compensate for each other in neural stem/progenitor populations during development (12, 29, 35); Sox17 and Sox18 show redundant functions in post-natal angiogenesis (25); and Sox4 and Sox11 can compensate for Sox12 during early embryonic development (20). The mRNAs for Sox3, 4, 5, 7, 10, 17 and 18 have been detected in whole intestine preparations (5), therefore it is reasonable that another Sox-factor(s) may be functionally compensating for the loss of Sox9 during enteroendocrine cell fate decisions. An intriguing observation from our study that may support a role of SOX9 in differentiation is that when SOX9 was increased to high levels in IEC-18 cells, there was a 
cellular phenotype that was characterized by a dramatic morphologic change in which cells acquired characteristics resembling a neuroendocrine morphology. We are cautious not to over-interpret these morphologic changes due to the absence of extrinsic influences on differentiation of IEC-18 cells in the in vitro context. In vivo studies are being conducted to address the role of SOX9 levels on differentiation of the intestinal epithelium.

An alternative hypothesis for the role of Sox9 in the intestinal epithelium that was not tested in the conditional Sox9 knockout studies is that SOX9 may be required for proper expression of enteroendocrine specific genes. To date, no direct target genes for SOX9 have been identified in cells of the small intestine epithelium. Although there were no other gross phenotypic abnormalities observed in the Sox9 conditional knockout mice besides the loss of Paneth cells and crypt hyperproliferation, variations in enteroendocrine-specific SOX9 target genes might exist with a less overt phenotype.

A generalized role for Sox 9 in modulating proliferation through the Wnt/\$-catenin pathway is becoming clear $(1,3,5,26)$. Sox9 has been reported to be a downstream target of Wnt-signaling acting in a feedback loop to repress Wnt-signaling, thus keeping proliferation under tight regulatory control (1, 3). The molecular mechanism responsible for this proliferation control has been established by overexpressing SOX9 in human colon cancer lines (3). In these studies high levels of SOX9 were able to decrease transcription of $\beta$-catenin target genes that positively regulate proliferation (i.e. c-myc, cyclinD1) and increase inhibitors of $\beta$-catenin-Tcf proliferative activity (i.e. ICAT, TLE2-4). Both of these events would presumably result in decreased proliferative capacity, which was not formally tested. The data presented in our study are consistent with the findings in human colon cancer cell lines by showing that high levels of SOX9 expression in the non-transformed IEC-18 cell line decreases the ß-catenin target gene, c-MYC. Our study further demonstrates a functional decrease in proliferation and 
expression of PCNA. Together, these data suggest that increasing SOX9 from low levels to high levels suppresses proliferation by decreasing ß-catenin signaling.

Since Sox9 appears to be a Wnt-target gene, one question our data poses is whether Wntsignaling is responsible for the high Sox9 levels observed in non-cycling enteroendocrine cells. A recent study, however, demonstrates that even at the enteroendocrine precursor stage, $\mathrm{Ngn}^{+}$cells differentiate into enteroendocrine cells independently of Wnt-signaling (43) indicating that Sox $9^{H I G H}$ enteroendocrine cells would develop independently of Wnt-signaling. To reconcile these studies with our data, we propose a bi-modal role for Sox9 where low levels of Sox9 modulate proliferative capacity in the stem/progenitor cell compartment in a Wnt-dependent manner, while high levels of Sox9 in enteroendocrine precursors ablate proliferative capacity and influence terminal differentiation/maturation in a Wnt-independent manner (Figure 6). Based on our in vivo data demonstrating that all Sox $9^{H I G H}$ cells are mature and post-mitotic, combined with the in vitro data showing that high levels of SOX9 abrogates the proliferative capacity of IEC-18 cells, we support a model where Sox9 expression becomes uncoupled from Wnt-signaling at some point during enteroendocrine fate specification and acts to repress the proliferative capacity of cycling enteroendocrine precursors at the final stages of terminal differentiation. Our results indicate the uncoupling event would occur downstream of $\mathrm{Ngn} 3$ since co-localization of $\mathrm{Ngn} 3$ and Sox $9^{\mathrm{HIGH}}$ is never observed in the Ngn3-fated progenitors. The crypt position for this 'uncoupling event' appears to occur on average at cell position +5 as there is a greater proportion of Sox $9^{H I G H}$ cells in this region of the crypts (Figure 2C). It has been previously reported that cell position +5 defines a niche for the differentiation of secretory lineages (4), thus the observation that Sox $9^{H I G H}$ cells in the crypt appear to primarily localize to cell position $+4-6$ (average +5 ) may point to an important source of extrinsic 
factors at this crypt position that may be influencing high levels of Sox9 expression and the development/maturation of enteroendocrine cells.

Subtle yet significant changes in the levels of steady-state gene expression have traditionally been difficult to assess at the cellular level because of the inability of existing technologies to accurately detect slight transcriptional variations. Transgenic reporter gene mice now enable high-resolution and real-time in vivo monitoring of gene transcription in normal and diseased states. Using this technology we have demonstrated that distinct levels of SOX9 in the intestinal epithelium are associated with both proliferative and post-mitotic cell types, and furthermore, that these variable SOX9 levels likely play an important role in both the control of proliferative capacity of stem/progenitor populations, and also the maturation of enteroendocrine cells. The Sox $9^{E G F P}$ mouse will also be a useful tool to investigate stem/progenitor populations during disease/injury and subsequent regeneration of the gut epithelium. Moreover, the ability to specifically FACS-isolate Sox9-expressing stem/progenitor populations for array-formatted gene expression studies will greatly enhance the ability to dissect important genetic pathways influencing normal gut homeostasis and diseased states involving the stem/progenitor cell compartment. 


\section{ACKNOWLEDGEMENTS:}

We would like to acknowledge the UNC Neuroscience Confocal Imaging Facility (P30 NS045892-04), the Center for GI Biology and Disease Imaging and Histology COREs (5P30DK034987), the UNC Chapel Hill Mutant Mouse Regional Resource Center, and the UNC Flow Cytometry CORE. We would also like to thank Priya Soni for technical support, and Drs. Kay Lund, Susan Henning, Michael Helmrath, Christopher Dekaney, Ajay Gulati, and Aaron Garrison for useful discussions.

\section{GRANTS:}

Funding was provided by the American Gastroenterological Association Research Scholar Award, the National Institutes of Health, 1-K01-DK080181-01, and the UNC-Chapel Hill Center for Gastrointestinal Biology and Disease, 5P30DK034987 (STM). 


\section{REFERENCES:}

1. Akiyama H, Lyons JP, Mori-Akiyama Y, Yang X, Zhang R, Zhang Z, Deng JM, Taketo MM, Nakamura T, Behringer RR, McCrea PD, and de Crombrugghe B. Interactions between Sox9 and beta-catenin control chondrocyte differentiation. Genes \& development 18: 1072-1087, 2004.

2. Barker N, van Es JH, Kuipers J, Kujala P, van den Born M, Cozijnsen M, Haegebarth A, Korving J, Begthel H, Peters PJ, and Clevers H. Identification of stem cells in small intestine and colon by marker gene Lgr5. Nature 449: 1003-1007, 2007.

3. Bastide P, Darido C, Pannequin J, Kist R, Robine S, Marty-Double C, Bibeau F, Scherer G, Joubert D, Hollande F, Blache P, and Jay P. Sox9 regulates cell proliferation and is required for Paneth cell differentiation in the intestinal epithelium. The Journal of cell biology 178: 635-648, 2007.

4. Bjerknes $\mathbf{M}$ and Cheng $\mathbf{H}$. The stem-cell zone of the small intestinal epithelium. III. Evidence from columnar, enteroendocrine, and mucous cells in the adult mouse. The American journal of anatomy 160: 77-91, 1981.

5. Blache P, van de Wetering M, Duluc I, Domon C, Berta P, Freund JN, Clevers H, and Jay P. SOX9 is an intestine crypt transcription factor, is regulated by the Wnt pathway, and represses the CDX2 and MUC2 genes. The Journal of cell biology 166: 37-47, 2004.

6. Bry L, Falk P, Huttner K, Ouellette A, Midtvedt T, and Gordon JI. Paneth cell differentiation in the developing intestine of normal and transgenic mice. Proceedings of the National Academy of Sciences of the United States of America 91: 10335-10339, 1994.

7. Cheng H. Origin, differentiation and renewal of the four main epithelial cell types in the mouse small intestine. II. Mucous cells. The American journal of anatomy 141: 481-501, 1974.

8. Cheng H. Origin, differentiation and renewal of the four main epithelial cell types in the mouse small intestine. IV. Paneth cells. The American journal of anatomy 141: 521-535, 1974. 
9. Cheng $\mathbf{H}$ and Leblond CP. Origin, differentiation and renewal of the four main epithelial cell types in the mouse small intestine. I. Columnar cell. The American journal of anatomy 141: 461-479, 1974.

10. Cheng $\mathbf{H}$ and Leblond CP. Origin, differentiation and renewal of the four main epithelial cell types in the mouse small intestine. III. Entero-endocrine cells. The American journal of anatomy 141: 503-519, 1974.

11. Cheng $\mathbf{H}$ and Leblond CP. Origin, differentiation and renewal of the four main epithelial cell types in the mouse small intestine. V. Unitarian Theory of the origin of the four epithelial cell types. The American journal of anatomy 141: 537-561, 1974.

12. Collignon J, Sockanathan S, Hacker A, Cohen-Tannoudji M, Norris D, Rastan S, Stevanovic M, Goodfellow PN, and Lovell-Badge R. A comparison of the properties of Sox-3 with Sry and two related genes, Sox-1 and Sox-2. Development (Cambridge, England) 122: 509-520, 1996.

13. Dekaney CM, Rodriguez JM, Graul MC, and Henning SJ. Isolation and characterization of a putative intestinal stem cell fraction from mouse jejunum. Gastroenterology 129: 1567-1580, 2005.

14. Denny P, Swift S, Brand N, Dabhade N, Barton P, and Ashworth A. A conserved family of genes related to the testis determining gene, SRY. Nucleic Acids Res 20: 2887, 1992.

15. Fantes J, Ragge NK, Lynch SA, McGill NI, Collin JR, Howard-Peebles PN, Hayward C, Vivian AJ, Williamson K, van Heyningen V, and FitzPatrick DR. Mutations in SOX2 cause anophthalmia. Nature genetics 33: 461-463, 2003.

16. Fre S, Huyghe M, Mourikis P, Robine S, Louvard D, and Artavanis-Tsakonas S. Notch signals control the fate of immature progenitor cells in the intestine. Nature 435: 964-968, 2005. 
17. Gong S, Zheng C, Doughty ML, Losos K, Didkovsky N, Schambra UB, Nowak NJ, Joyner

A, Leblanc G, Hatten ME, and Heintz N. A gene expression atlas of the central nervous system based on bacterial artificial chromosomes. Nature 425: 917-925, 2003.

18. Gordon PV, Paxton JB, and Fox NS. A methodology for distinguishing divergent cell fates within a common progenitor population: adenoma- and neuroendocrine-like cells are confounders of rat ileal epithelial cell (IEC-18) culture. BMC cell biology 6: 2, 2005.

19. Graham V, Khudyakov J, Ellis P, and Pevny L. SOX2 functions to maintain neural progenitor identity. Neuron 39: 749-765, 2003.

20. Hoser M, Potzner MR, Koch JM, Bosl MR, Wegner M, and Sock E. Sox12 deletion in the mouse reveals non-reciprocal redundancy with the related Sox4 and Sox11 transcription factors. Molecular and cellular biology, 2008.

21. Kamachi Y, Uchikawa M, Tanouchi A, Sekido R, and Kondoh H. Pax6 and SOX2 form a coDNA-binding partner complex that regulates initiation of lens development. Genes \& development 15: 1272-1286, 2001.

22. Kist R, Schrewe H, Balling R, and Scherer G. Conditional inactivation of Sox9: a mouse model for campomelic dysplasia. Genesis 32: 121-123, 2002.

23. Korinek V, Barker N, Moerer P, van Donselaar E, Huls G, Peters PJ, and Clevers H. Depletion of epithelial stem-cell compartments in the small intestine of mice lacking Tcf-4. Nature genetics 19: 379-383, 1998.

24. Lobachevsky PN and Radford IR. Intestinal crypt properties fit a model that incorporates replicative ageing and deep and proximate stem cells. Cell Prolif 39: 379-402, 2006. 
25. Matsui T, Kanai-Azuma M, Hara K, Matoba S, Hiramatsu R, Kawakami H, Kurohmaru M, Koopman P, and Kanai Y. Redundant roles of Sox17 and Sox18 in postnatal angiogenesis in mice. Journal of cell science 119: 3513-3526, 2006.

26. Mori-Akiyama Y, van den Born M, van Es JH, Hamilton SR, Adams HP, Zhang J, Clevers H, and de Crombrugghe B. SOX9 is required for the differentiation of paneth cells in the intestinal epithelium. Gastroenterology 133: 539-546, 2007.

27. Overton PM, Meadows LA, Urban J, and Russell S. Evidence for differential and redundant function of the Sox genes Dichaete and SoxN during CNS development in Drosophila. Development (Cambridge, England) 129: 4219-4228, 2002.

28. Pevny LH and Lovell-Badge R. Sox genes find their feet. Curr Opin Genet Dev 7: 338-344, 1997.

29. Pevny LH, Sockanathan S, Placzek M, and Lovell-Badge R. A role for SOX1 in neural determination. Development (Cambridge, England) 125: 1967-1978, 1998.

30. Pfaffl MW. A new mathematical model for relative quantification in real-time RT-PCR. Nucleic acids research 29: e45, 2001.

31. Pinto D, Gregorieff A, Begthel H, and Clevers H. Canonical Wnt signals are essential for homeostasis of the intestinal epithelium. Genes \& development 17: 1709-1713, 2003.

32. Potten CS, Booth C, Tudor GL, Booth D, Brady G, Hurley P, Ashton G, Clarke R, Sakakibara S, and Okano H. Identification of a putative intestinal stem cell and early lineage marker; musashi-1. Differentiation 71: 28-41, 2003.

33. Que J, Okubo T, Goldenring JR, Nam KT, Kurotani R, Morrisey EE, Taranova O, Pevny LH, and Hogan BL. Multiple dose-dependent roles for Sox2 in the patterning and differentiation of anterior foregut endoderm. Development (Cambridge, England) 134: 2521-2531, 2007. 
34. Radford IR and Lobachevsky PN. An enteroendocrine cell-based model for a quiescent intestinal stem cell niche. Cell Prolif 39: 403-414, 2006.

35. Rizzoti K, Brunelli S, Carmignac D, Thomas PQ, Robinson IC, and Lovell-Badge R. SOX3 is required during the formation of the hypothalamo-pituitary axis. Nature genetics 36: 247-255, 2004.

36. Sangiorgi E and Capecchi MR. Bmi1 is expressed in vivo in intestinal stem cells. Nature genetics 40: 915-920, 2008.

37. Scaffidi P and Bianchi ME. Spatially precise DNA bending is an essential activity of the sox2 transcription factor. The Journal of biological chemistry 276: 47296-47302, 2001.

38. Schonhoff SE, Giel-Moloney M, and Leiter AB. Minireview: Development and differentiation of gut endocrine cells. Endocrinology 145: 2639-2644, 2004.

39. Stanger BZ, Datar R, Murtaugh LC, and Melton DA. Direct regulation of intestinal fate by Notch. Proceedings of the National Academy of Sciences of the United States of America 102: 1244312448, 2005.

40. Taranova OV, Magness ST, Fagan BM, Wu Y, Surzenko N, Hutton SR, and Pevny LH. SOX2 is a dose-dependent regulator of retinal neural progenitor competence. Genes \& development 20: 1187-1202, 2006.

41. van Es JH, van Gijn ME, Riccio O, van den Born M, Vooijs M, Begthel H, Cozijnsen M, Robine S, Winton DJ, Radtke F, and Clevers H. Notch/gamma-secretase inhibition turns proliferative cells in intestinal crypts and adenomas into goblet cells. Nature 435: 959-963, 2005.

42. Wagner T, Wirth J, Meyer J, Zabel B, Held M, Zimmer J, Pasantes J, Bricarelli FD, Keutel J, Huster E, Wolf U, Tommerup N, Schempp W, and Scherer G. Autosomal sex reversal and Campomelic Dysplasia are caused by mutations in and around the Sry-related gene SOX9. Cell 9: 11111120, 1994. 
43. Wang Y, Giel-Moloney M, Rindi G, and Leiter AB. Enteroendocrine precursors differentiate independently of Wnt and form serotonin expressing adenomas in response to active beta-catenin. Proceedings of the National Academy of Sciences of the United States of America 104: 11328-11333, 2007.

44. Weiss MA. Floppy SOX: mutual induced fit in hmg (high-mobility group) box-DNA recognition. Molecular endocrinology (Baltimore, Md 15: 353-362, 2001.

45. Wissmuller S, Kosian T, Wolf M, Finzsch $\mathbf{M}$, and Wegner M. The high-mobility-group domain of Sox proteins interacts with DNA-binding domains of many transcription factors. Nucleic acids research 34: 1735-1744, 2006.

46. Yang Q, Bermingham NA, Finegold MJ, and Zoghbi HY. Requirement of Math1 for secretory cell lineage commitment in the mouse intestine. Science 294: 2155-2158, 2001. 


\section{FIGURE LEGENDS:}

Figure 1 - Expression analysis of Sox $9^{E G F P}$ in the small intestine - (A) Sox $9^{E G F P}$ expression in jejunal crypts is localized to the base in intercalating CBCs and supra-Paneth cell locations. There are two distinct levels termed 'HI' and 'LO'. (B) Sporadic Sox $9^{E G F P H I}$-expressing cells are found throughout the villus epithelium. White arrows mark representative Sox $9^{E G F P H I}$ cells. Image at far right is a high magnification to demonstrate morphology. (C) Sox $9^{E G F P}$ expression does not colocalize with granulated Paneth cells. (D) Molecular confirmation that Sox $9^{E G F P}$ is not expressed in Paneth cells as marked by Lysozyme.

Figure 2 - Validation of the Sox $9^{E G F P}$ transgene and whole-crypt analysis of SOX9 expression in Paneth cells - (A) SOX9 protein levels directly correlate with Sox ${ }^{E G F P}$ transgene expression levels. The nucleus of the Sox $9^{\mathrm{EGFHI}}$ cell located higher up the crypt-villus is not in the focal plane of the confocal image and thus endogenous SOX9 is not observable. (B) Numbering scheme used to quantify the location of $\operatorname{Sox} 9^{E G F P H I}$ cells. Cell position 1 is located at the very base of the crypt. (C) Distribution of Sox $9^{E G F P H I}$ cells in the small intestine crypt. Variation is depicted as the standard error of the mean of three individuals counting one cell position difference either up or down the average cell position along crypt-villus axis. (D) Whole crypts were immunostained for Lysozyme and SOX9 and digitally reconstructed from $1 \mu \mathrm{m}$ confocal slices. By assessing every Paneth cell in an intact jejunal crypt, two populations of Paneth cells can be define by either the presence or absence of SOX9. The ratio of $\mathrm{SOX9}^{+}$to SOX9 ${ }^{-}$Paneth cells was on average $1: 1$ ( $\mathrm{n}=5$ intact crypts, SOX9 ${ }^{+}$mean=2.6/crypt, S.E.M.=1.5; SOX9- mean=2.6/crypt S.E.M.=1.1). The images represent two different representative crypts (designated A and B). Each image represents a different optical slice on the Z-plane. Blue = 
nuclei, Red = SOX9, Green = Lysozyme. RED arrows point to SOX9 positive Paneth cells. WHITE arrows point to SOX9 negative Paneth cells.

Figure 3 - Gene expression analysis in isolated populations of Sox $9^{\text {EGFP }}$-expressing cells - (A) FACS histogram demonstrates the three distinct populations of Sox $9^{E G F P}$-expressing cells. Sox $9^{E G F P}$ cells were sorted based on EGFP intensities (either Negative, HI, or LO). (B) The FACS sort based on EGFP levels (and thus Sox9 mRNA levels) was validated as Sox $9^{\text {EGFPHI }}$ cells express 5-fold higher (S.E.M. = 1.2fold) Sox9 mRNA than Sox $9^{E G F P L O}$ cells. Sox $9^{E G F P L O}$ cells have 10.2-fold more Notch1 (S.E.M.=0.65fold) and 11.4-fold more Hes1 (S.E.M.=1.3-fold) mRNA compared to Sox $9^{\text {EGFPHI }}$ cells. Images to the right of the graph represent the cells post-sort. (C) Sox $9^{E G F P L O}$ cells are enriched in stem/progenitor cell marker genes. Sox9 (mean=6.7-fold higher, S.E.M.=2.3-fold), Lgr5 (mean=8.9-fold, S.E.M.=3.8-fold), Msi1 (mean=13.3, S.E.M.=3.6-fold); all $p$ values $<0.001$.

Figure $4-\operatorname{Sox} 9^{E G F P H I}$ cells are post-mitotic Enteroendocrine cells - Sox $9^{E G F P H I}$ cell lineage was identified by co-localization of EGFP with enteroendocrine-specific markers (A) Substance-P, (B) Chromogranin A. Post-mitotic status of Sox $9^{E G F P H I}$ cells was assessed by co-localization of EGFP with (C) Ki67 and (D) Ngn3. WHITE arrows depict representative cells. All images are 1 um confocal optical slices. Note: (A) is EGFP fluorescence, and (B-C) is immunofluorescence staining for EGFP. Immunodetection of EGFP is required due to destruction of EGFP fluorescence by the antigen retrieval methods.

Figure 5 - Phenotypic analysis of lentiviral-mediated increases in SOX9 levels - (A) Schematic of Lentiviral construct generated. The control lentiviral vector contains all the elements as the SOX9 
lentiviral vector except the Sox9 cDNA. EGFP is translated from an Internal Ribosomal Entry Site (IRES) as a reporter gene to assess infection. The Puromycin gene is included to allow positive selection for viral integration into the genome. cDNA expression is driven by strong constitutive promoters (either CMV or PGK). (B) Validation of the SOX9 lentivirus. Forty-eight hours post-infection, IEC-18 cells were assessed for SOX9 by immunostaining (red), and EGFP autofluorescence (green). (C) IEC-18 cells were infected with equivalent titers of either control lentivirus or SOX9 lentivirus and selected with puromycin to deplete the cultures of untransduced cells. Equivalent numbers of cells were plated and allowed to grow for an additional 5 days. Images (left two panels) depict monolayers of IEC-18 cells that emerged in the control infected cells that express low endogenous levels of SOX9 (red). Right two panels depict cells infected with the SOX9 lentivirus. No proliferation (as detected by clonal populations) was observed in SOX9 lentivirus infected cells. Immunostaining for SOX9 (red) validates high expression of SOX9 in these cells. (D) Immunoblotting analysis of whole cell extracts made from control-virus (left lane) or SOX9-virus infected (right lane) IEC-18 cells. Blots were probed for c-MYC and PCNA using ß-actin expression as an internal control. (E) Morphologic phenotypes of SOX9 lentivirus infected IEC-18 cells. Note neuroendocrine-like morphologies (axonal/dendritic processes and dense vesicle formations) were evident 6-8 days post-infection.

\section{Figure 6 - Model describing the relationship between Wnt and Sox9 in the adult intestinal epithelium}

- Multipotent CBCs universally express low-levels of Sox9 in a Wnt-dependent manner. Post-Ngn3 lineage specification, instructive intrinsic and/or extrinsic signaling increases Sox9 expression to high levels in a Wnt-independent manner decreasing proliferative capacity and promoting terminal differentiation/maturation of enteroendocrine cells. 
Figure S1 - Sox $9^{E G F P}$ does not co-localize with Lysozyme - Whole crypts were isolated from Sox $9^{E G F P}$ mice and stained for the Paneth cell marker Lysozyme (Red). Three-dimensional confocal imaging was conducted to assess staining throughout the entire crypt. Nuclei were stained with Draq5 (Blue). Sox $9^{E G F P}$ (Green). Each frame represents a $1 \mu \mathrm{m}$ optical section.

Figure S2 - SOX9-expression defines two populations of Paneth cells - Whole crypts were isolated from non-transgenic mice and stained for the Paneth cell marker Lysozyme (Green) and for SOX9 (Red). Three-dimensional confocal imaging was conducted to assess staining throughout the entire crypt. Nuclei were stained with Draq5 (Blue). This 3-D reconstruction is representative of all crypts analyzed (n=5). Each frame represents a $1 \mu \mathrm{m}$ optical section. 


\section{A So $\times 9^{\text {EGFP }}$}

B SOX9EGFP
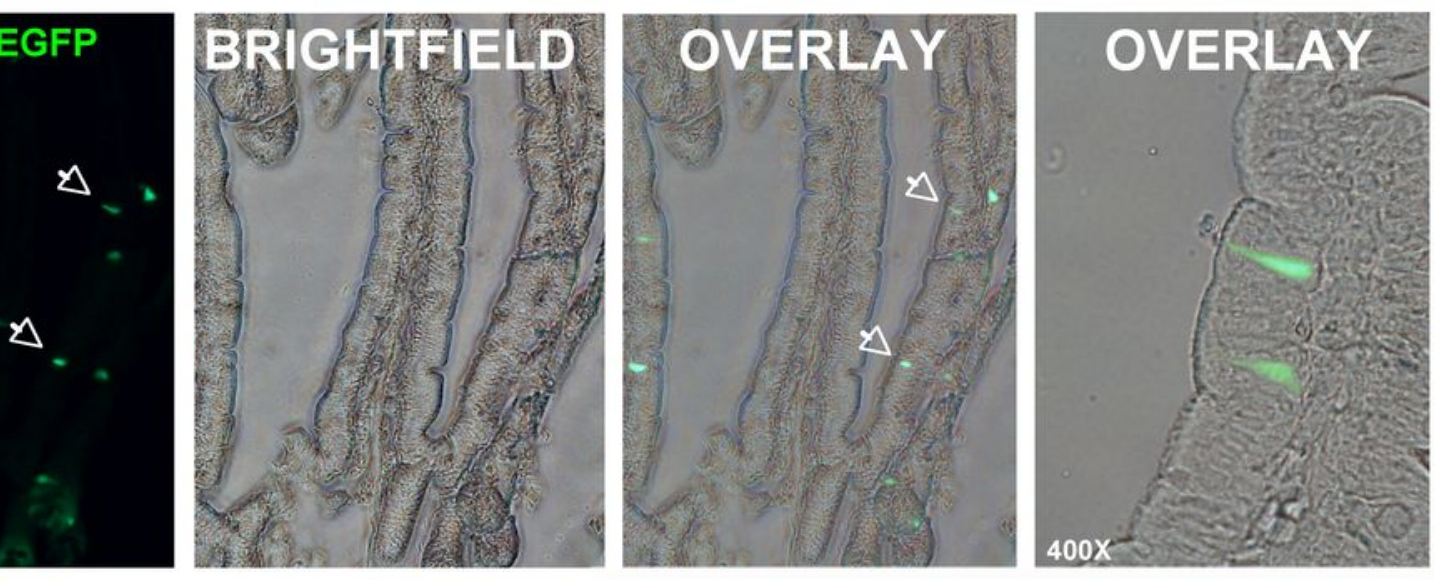

C

SOX9EGFP/NUCLEI

$600 x$

D
Sox9EGFP

3)

\section{SOX9EGFP/BRIGHTFIELD}



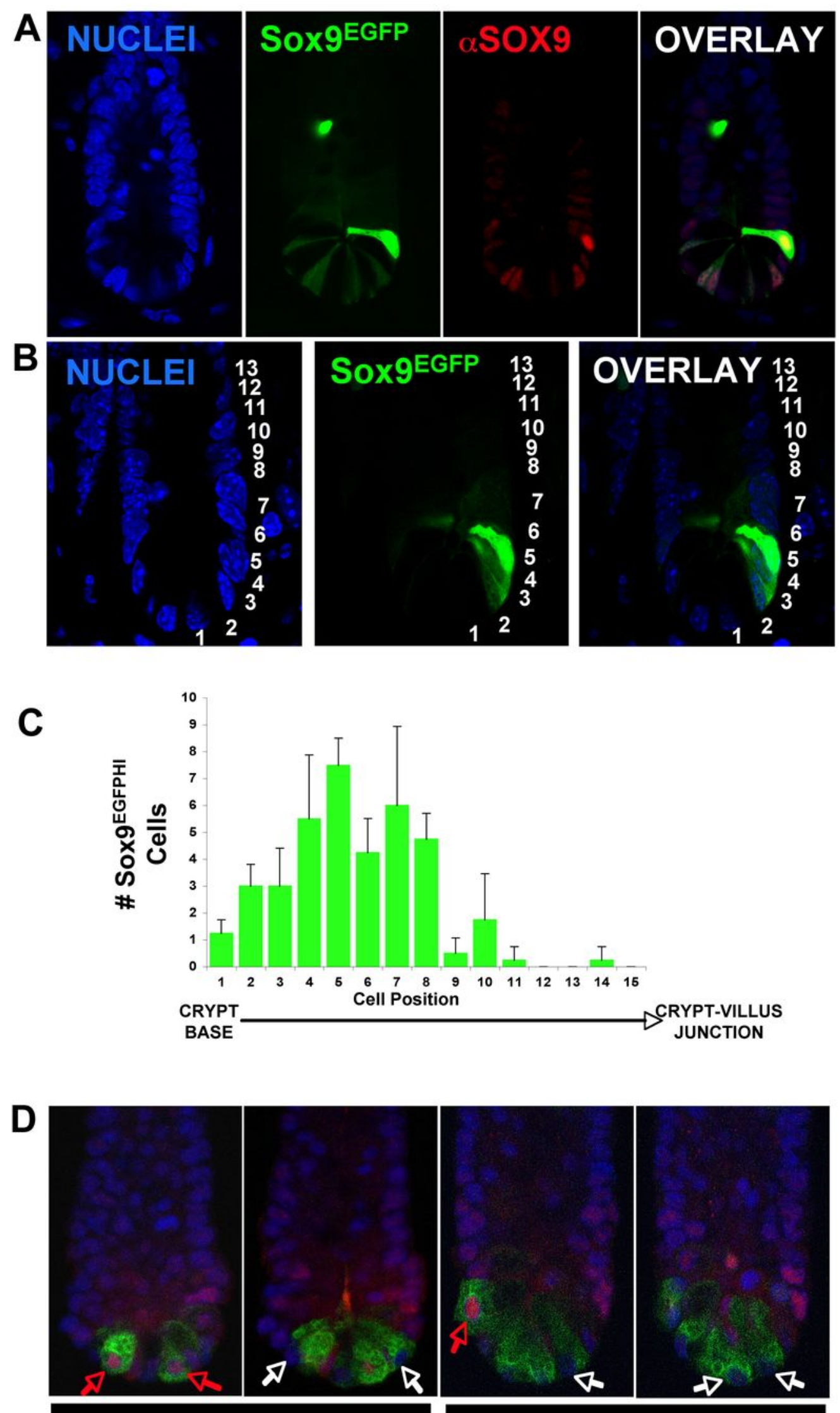

Crypt A

Crypt B

Figure 2 


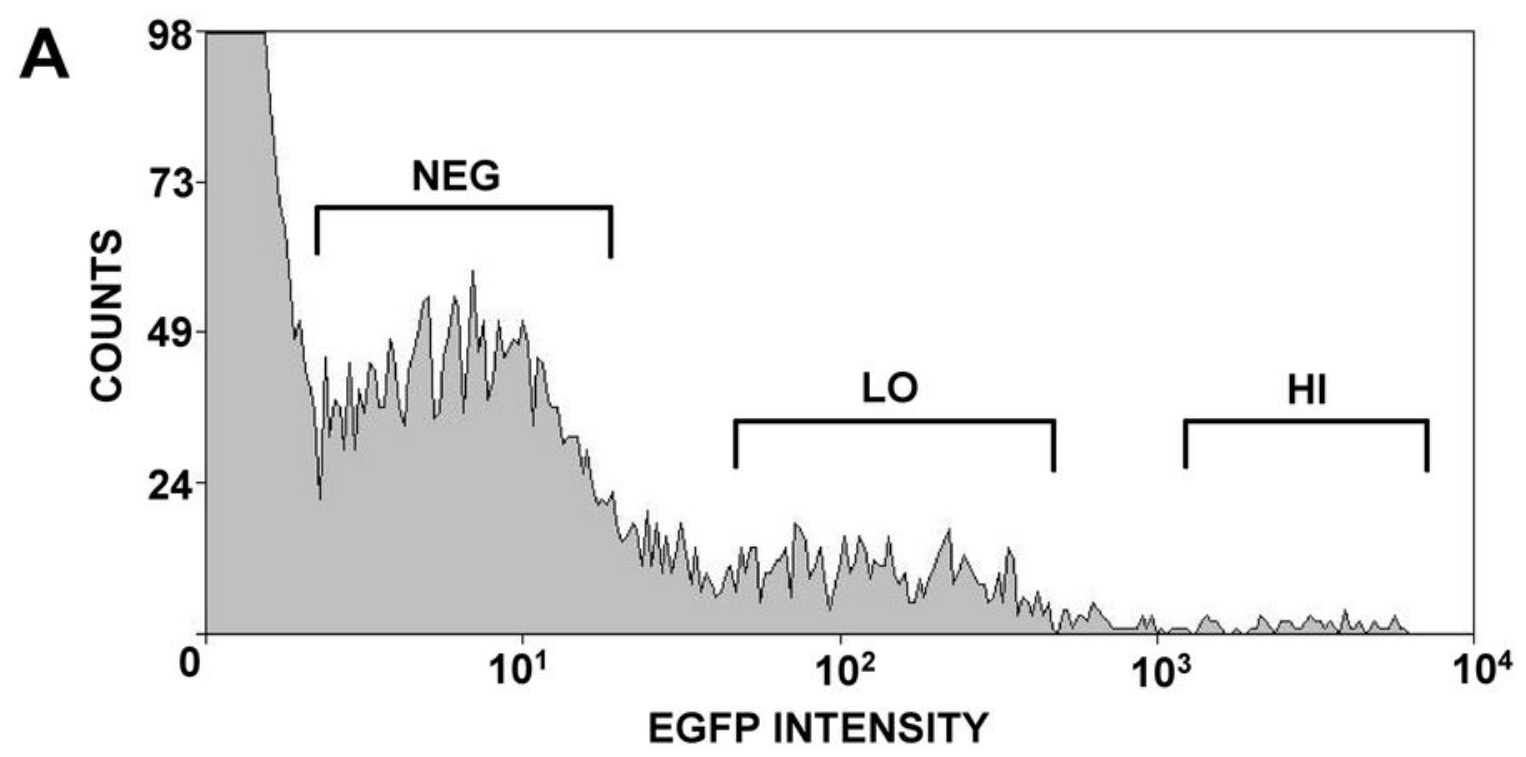

B
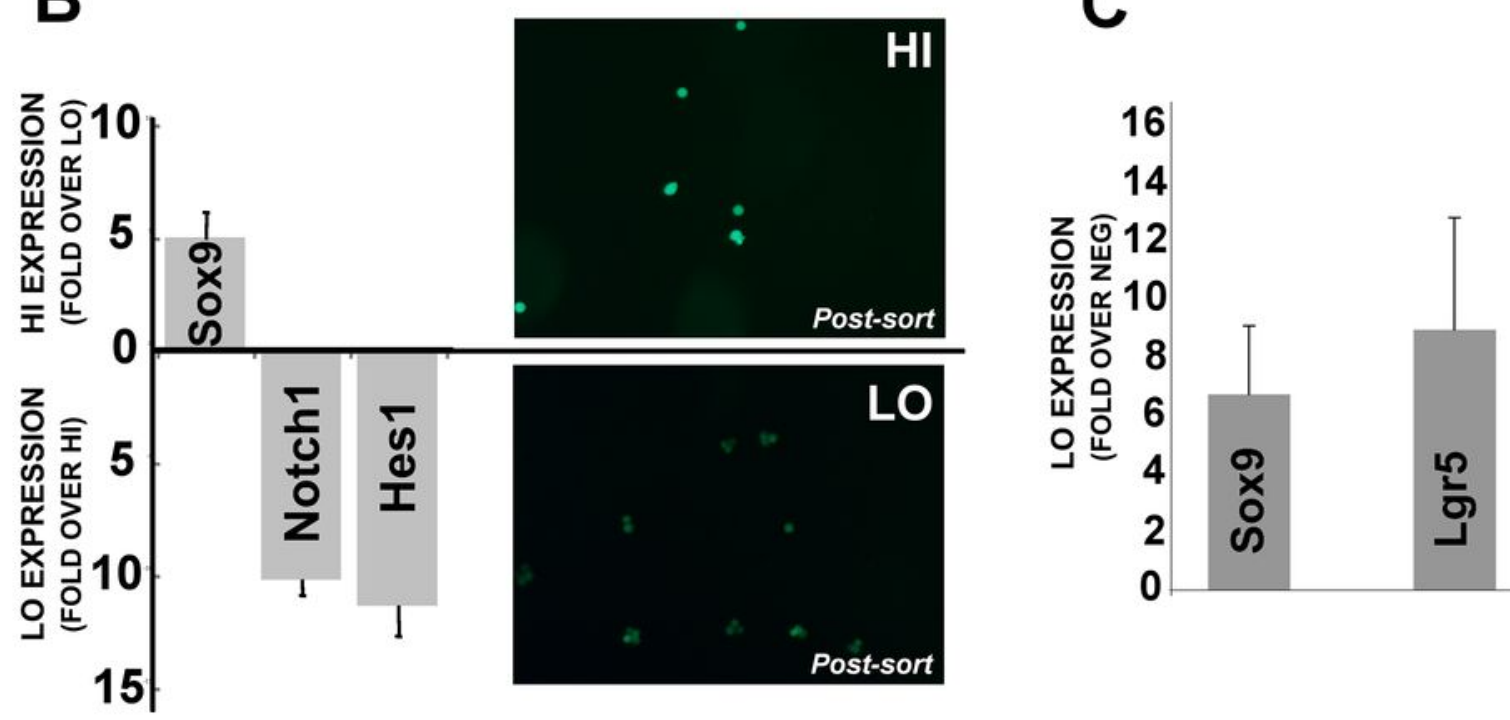

Figure 3 


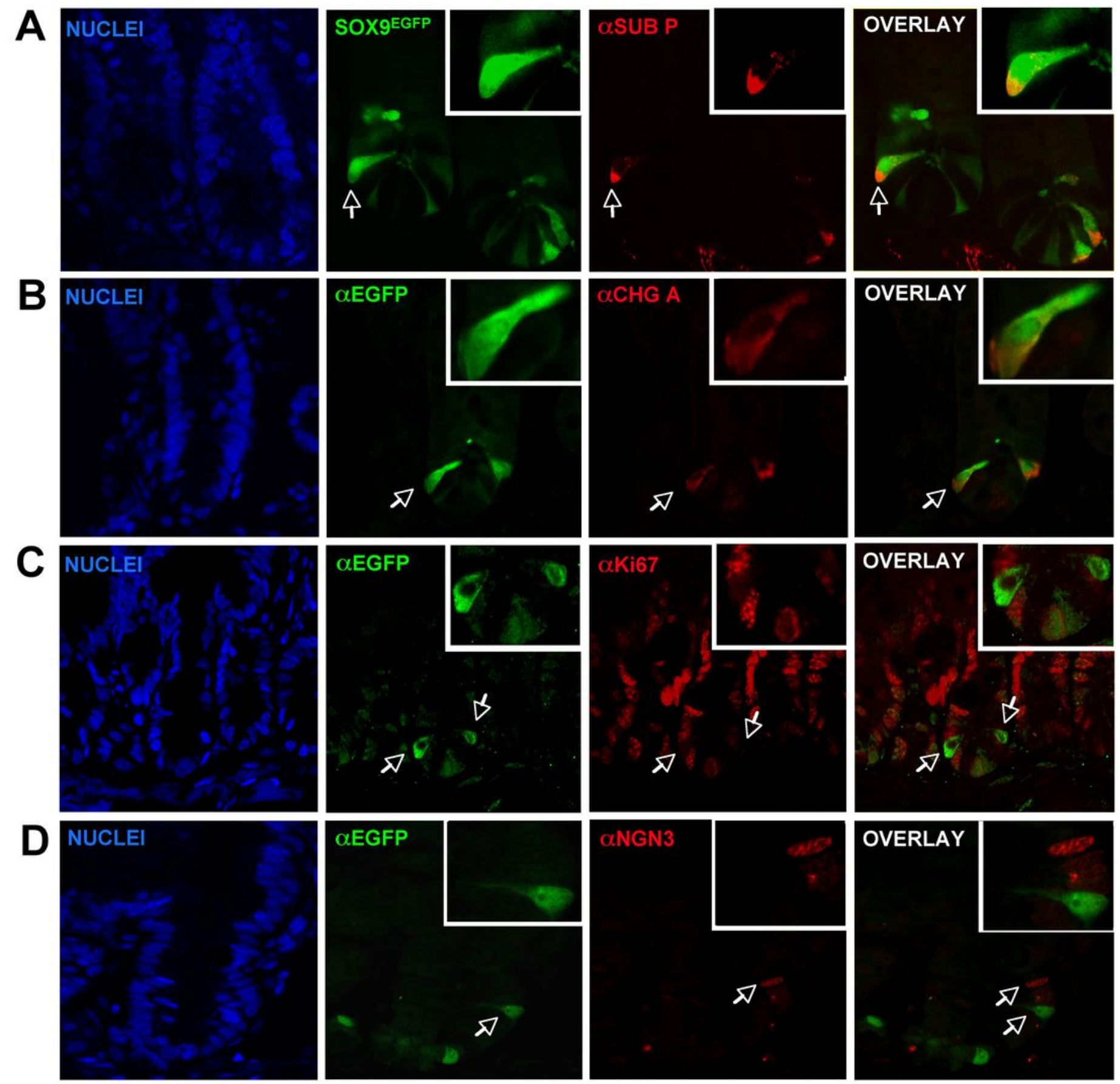

Figure 4 
A

LTR -CMV IRES EGFP PGK PURO - LTR CONTROL LTR-CMV SOX9 IRES EGFP -PGK PURO -LTR SOX9

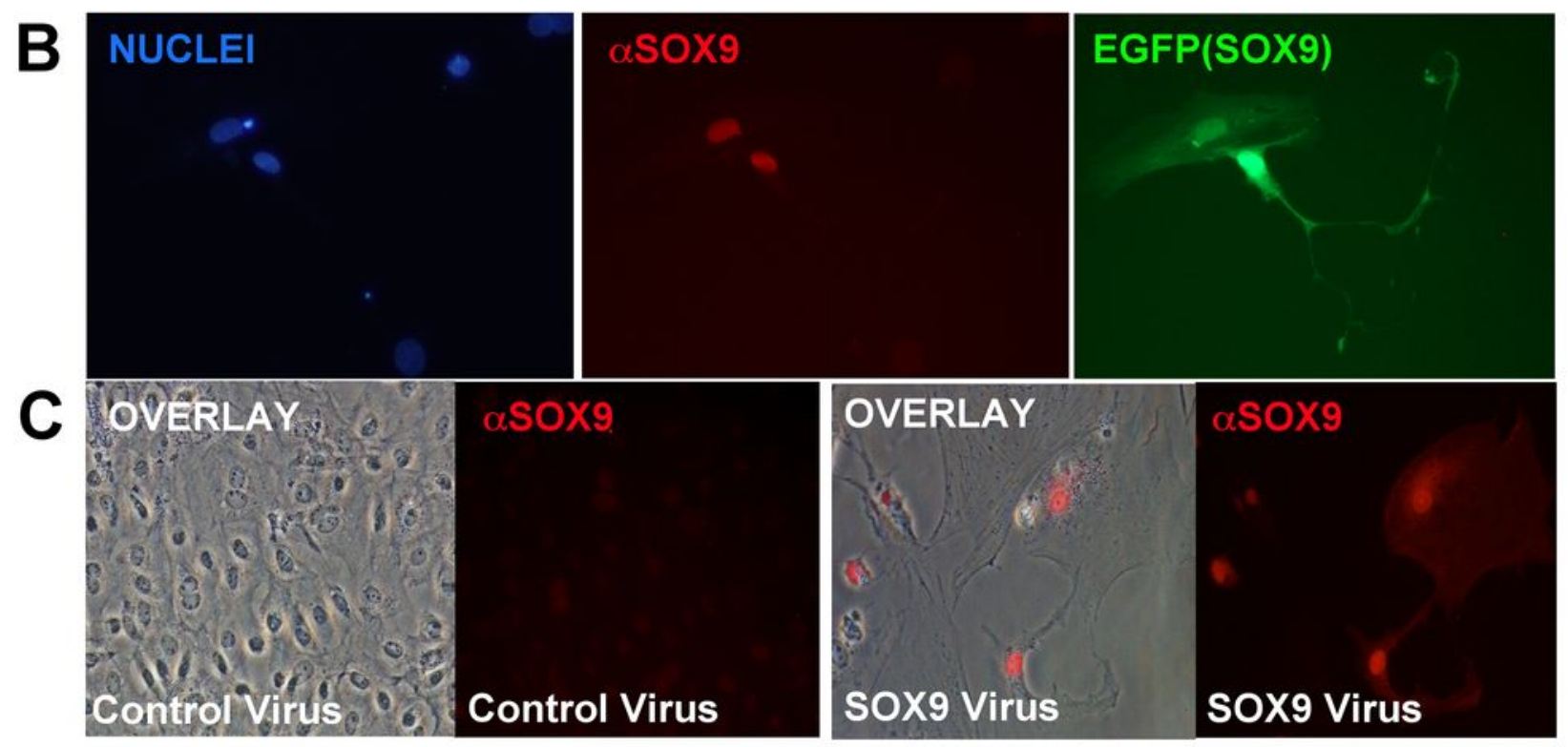

D CONvirus SOX9virus E EGFP(SOX9) OVERLAY

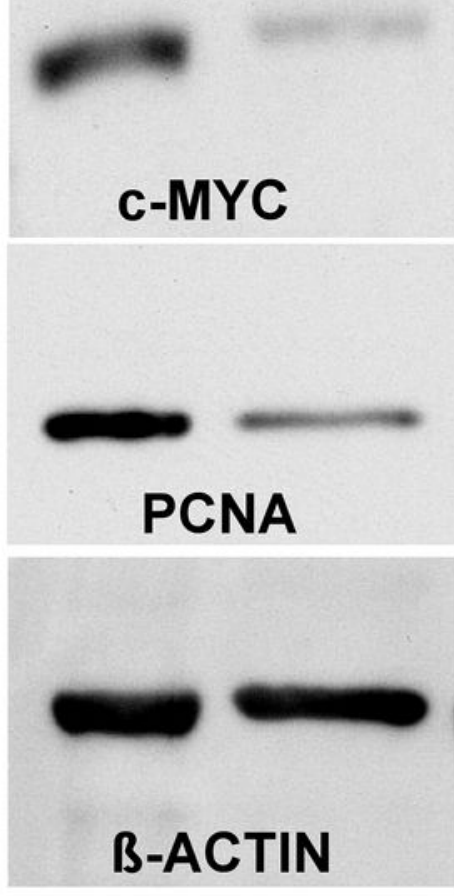

Figure 5 


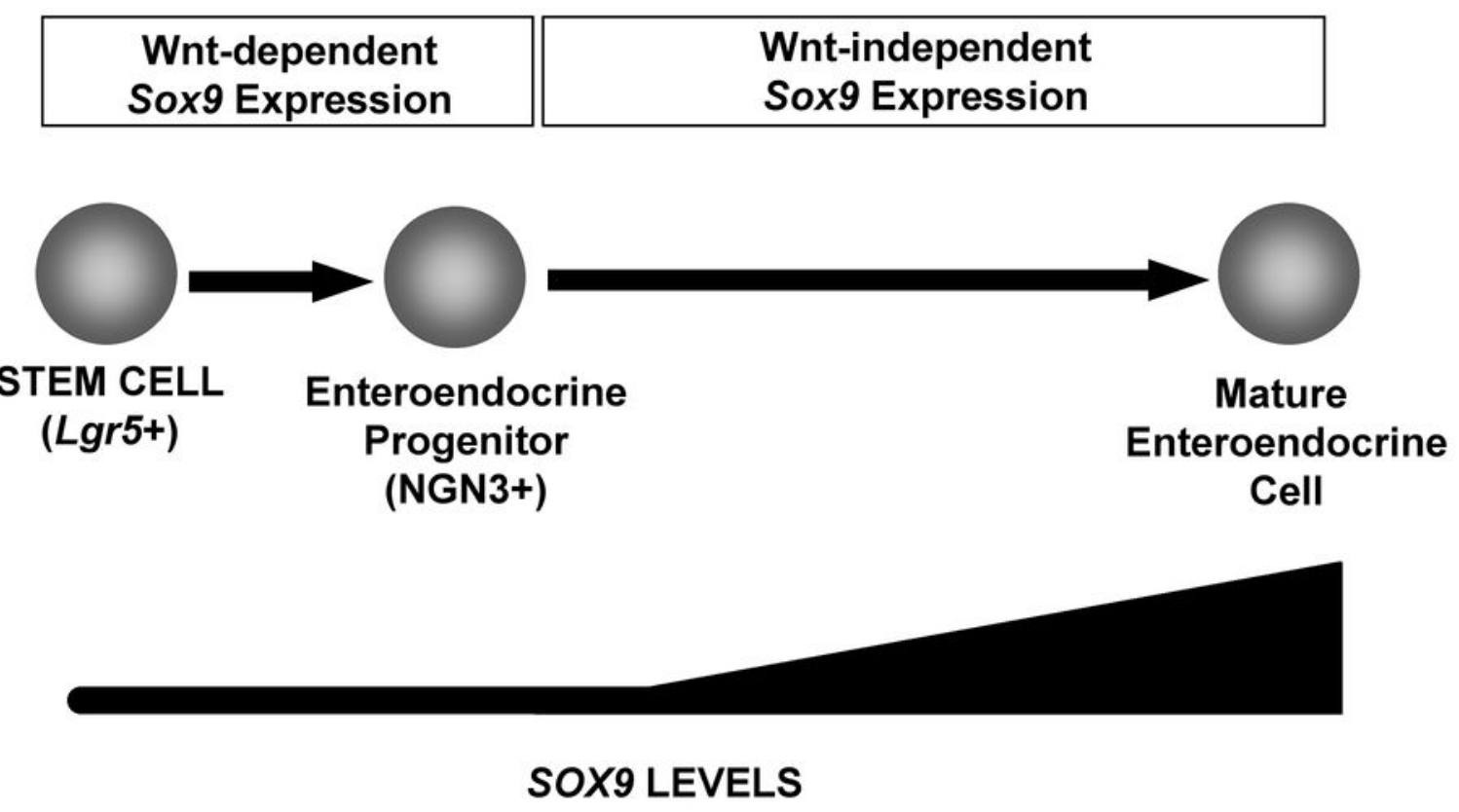

Figure 6 